\title{
As marcas da violência na constituição da identidade de jovens da periferia
}

Carla Araújo

PontifíciaUniversidadeCatólicadeMinasGerais

Resumo

Este trabalho foi baseado em uma pesquisa, de caráter investigatório, que buscou compreender as vivências escolares de jovens alunos moradores da Vila da Luz, que se localiza na periferia de Belo Horizonte, cujo cotidiano é marcado pela violência, pela insegurança pública e pela exclusão social.

Examinou-se como as vivências fora da escola invadem o cotidiano e reorientam atitudes e comportamentos dos alunos entre si, e destes em relação aos professores e a outros agentes escolares. Buscou-se caracterizar sociologicamente 0 ambiente escolar como espaço de interações complexas, no qual violência simbólica e agressão física se entrecruzam, propiciando um tipo de vivênciaescolarbaseada no medo e na ansiedade. Focalizou-se a experiência e as representações sociais dos jovens alunos, com o intuito de compreender como eles constroem suas identidades, tendo a violência como pano de fundo em suas relações grupais e interpessoais.

Assim, a investigação abriu possibilidades para se pensar a escola como espaço de medi ação decon fli tosedecon vi vên cia da diversidade cultural e social. Centrado em uma metodologia de pesquisa participante com ênfase no modelo interpretativista, este estudo permitiu aprofundar questões referentes à educação e subjetividade, sob a óti ca deal gunsteó ri cosimportan tes, tais como Anthony Giddens, Norbert Elias e Erik Erikson.

\author{
Palavras-chave \\ Juventude - Violência - Escola - Identidade.
}




\section{School experiences of Brazilian youngsters: the effects of violence in the construction of their identities}

Carla Araújo

PontifíciaUniversidadeCatólicadeMinasGerais

\section{Abstract}

This work deals with the school experiences of young pupils living in Vila da Luz - a neighborhood on the outskirts of Belo Horizonte, Brazil - whose daily life is characterized by violence, public insecurity, and social exclusion.

The exploratory study examined how experiences outside school, particularly in Vila da Luz, infringe on their daily lives and reorient pupil's attitudes and behaviors among themselves and towards teachers and other school workers. The school environment was sociologically characterized as a space of complex interactions, in which symbolicviolenceand physical aggression intersect, giving rise to a school experience based on fear and anxiety. The experiences and social representations of young pupils were emphasized with a view to understand how they build their identities when their group and interpersonal relations take place against a background of violence.

Thus, the investigation offered possibilities to think the school as a space for the mediation of conflicts and the coexistence of social and cultural diversity. Centered on a participative research methodology with emphasis on the interpretative model, this study permitted developing issues concerning education and subjectivity under the optics of some important theorists such as A nthony Giddens, Norbert Elias, and Erik Erikson.

Keywords

Youth - Violence - School - Identity. 
Medo, imobilização e

hipótese da escola

Quando esta pesquisa foi iniciada, uma ampla investigação preliminar sobre quais as regiões da cidade estariam vivenciando de forma acentuada a violência nas escolas foi feita, partindo de um pequeno levantamento que já havia sido realizado pela Secretaria Municipal da Educação. ${ }^{1}$ Ao chegar à escola "Professora Inês Gonçalves" um fato era novo e singular se com para do aosdeou trasesco las: umalu no havia comparecido, armado, à aula. A direção da escola supôs que esse aluno fosse morador de um bairro pobre, a Vila da Luz, motivo pelo qual ele, por alguma razão, precisaria levar a arma para a escola. Foi nesse momento que a dimensão do contexto da Vila passava a ser 0 centro de nossa atenção. A escola atendia os alunos dessa Vila, mas também alunos de bairros mais próximos da escola, de maior poder aquisitivo. Somente no decorrer da pesquisa é que pudemos ver as rivalidades entre a Vila da Luz e uma outra Vila, o Conjunto $A B C{ }^{2}$ Para chegare sair desta vila é preci so passar pela Vila da Luz, o que agrava a situação de confronto entre essas duas comunidades, como observamos pelos relatos dos jovens da Vila da Luz no decorrer da pesquisa. A própria escola se surpreendeu com essa rivalidade e não tinha a dimensão dessa repercussão em seu interior. A hi pó tesedaesco la paraosatos devi o lên ciaque ocorriam em suas dependências, em especial para o fato de um aluno comparecer armado, era a violência do local de moradia do jovem, conhecida por toda a comunidade próxima.

Vivenciar a violência no local de moradia (no caso, a Vila da Luz) pode se tornar um elemen to constitu in tedaiden tidadedosjo vens? $\mathrm{E}$ mais: quando esses jovens vão para a escola, como se comportam, se organizam, convivem e criam estratégias de convivência com os outros alunos? A imagem que os outros alunos fazem dos jovens da Vila da Luz também participa na constituição da identidade deles? Nesse senti- do, as falas dosjo vensso bre suas vi vên ci asna Vila da Luz foram imprescin díveisparaacompreensão das questões acima colocadas.

Atores, identidade e metodologia - a construção

As discussões teóricas das categorias utilizadas para a análise das questões propostas partiram, essencialmente, dos referenciais de Anthony Giddens, Norbert Elias e E. Erikson. Foram utilizadas nessa pesquisa a observação, as conversas informais com os alunos dentro das salas de aula, durante o recreio, nas entradas e saídas da escola, etc., além das entrevistas semi-estruturadas, atividades em grupo a partir de exposição de gravuras, da exibição (parcial) de uma fita de vídeo ${ }^{3}$ e de associações livres a partir da palavra indutora jovem. As atividades em grupo fo ramfilmadas pelos próprios alunos, com exceção das associações livres, que não foram filmadas. Essa metodologia se justificou pela necessidadede não expor os jovens moradores da Vila da Luz separando- os dos demais e sobretudo pela di ficuldade encontrada em reuni-los ao mesmo tem po etam bém nos mes mos dias (há um alto índice de absenteísmo).

A intencionalidade dos atos, as percepções dos atores e o caráter intersubjetivo dos significados foram altamente privilegiados. Já no que concerne à identidade, buscou-se

1. Esse levantamento foi feito por meio de um questionário enviado para as diretorias das escolas em Belo Horizonte, no qual elas deveriam responder perguntas sobre a violência: se existia ou não violência na escola, qual era o tipo de violência mais comum, etc. De posse desse material, partimos para a Regional (conjunto de bairros) onde a violência estava sendo mais citada. Todas as escolas de ensino noturno que atendiam alunos no ensino regular noturno ( 5 a a 8 a série) foram, inicialmente, entrevistadas, antes da escolha pela escola "Professora Inês Gonçalves".

2. O Conjunto ABC fica localizado nos "fundos" da Vila da Luz. Esse conjunto foi "projetado" pela Prefeitura para transferir moradores de um local onde não havia a menor infra-estrutura, segundo relato dos jovens entrevistados.

3. Fita: $A B C D$ J ovens - Sindicato dos Metalúrgicos do $A B C$ São Paulo e TV dos Trabalhadores. 
entendê-la fcomo um conjunto de imagens, representações, conceitos de si, sendo considerado, especialmente, o caráter dialético de sua construção, a saber, a importância da alteridade nesse processo. Assim, foi necessário a inclusão, na metodologia, de procedimentos que pudessem fornecer dados para a compreensão da importância do outro nesse processo. ${ }^{4}$ Por ser dialética, além de determinada, a identidade é também determinante, pois o jovem tem um papel ativo, quer na construção desse contexto a partir de sua interação, quer na sua apropriação. A iden ti da de só podeser constru í da a partir dessa interação. Interessou-nos, portanto, a percepção que os alunos têm uns dos outros e da violência que testemunham e vivenciam em seus locais de mo ra dia (em especial naVila da Luz) ena escola.

Sendo, os jovens, sujeitos histórico-sociais, a análise, obviamente, não se mantém estática durante o passar dos anos e os autores absorvem as mudanças em seus trabalhos. De acordo com o momento histórico, há interferências nas produções que vão sendorealizadas pelos diversos autores dessa temática. A juventude tem sido, de acordo com o momento histórico, considerada de modos variados. $\mathrm{Na}$ década de 1960, por exemplo, era entendida como um "problema", na medida em que podia ser identificada como geradora de uma crise de valores e de um conflito de gerações. Já na década de 1970, as questões eram aquelas relacionadas ao jovem e o trabalho (emprego).

Se pensarmos na juventude associada ao caráter transitório que caracterizaesseperío do, podemos defini-la como um conjunto social deri vado deuma determi na dafaseda vida, com enfoque e ênfase nos aspectos geracionais. Nesse sentido, várias po dem ser asfun ções atribuídas à juventude, cujo significado diferencia-se em cada contexto sócio-histórico. Uma delas seria a de agente revitalizador: um recurso latente de energia e força a ser usado pela sociedade como um dinamismo criador que objetiva dar novas orientações à sociedade ( $\mathrm{M}$ annheim,1970).
A modernidade associa o jovem a uma idéia de futuro (Sposito,1999). No entanto, cabe lembrar que, por mais que a juventude possa ser entendida como permanente e, portanto, com características próprias, ela também é marcada por "rituais de passagem" que nos apontam para sua transitoriedade. Esses rituais existem e não há como negá- los. Pereira (2000) mostra como as crianças vão deixando de brincar, marcando assim um ritual de passagem da infância para a adolescência. Assim, há mudanças que vão se operar com 0 jovem e que não voltarão a se repetir da mesma maneira no futuro.

É necessário contextualizar, sempre, de qual juventude estamos nos referindo. Assim, talvez devêssemos ter em mente que, quando falamos de "juventude", na realidade estamos falando de "juventudes", no plural (Sposito, 1998). A definição de juventude é bastante flexível, pois ela é carregada de significados culturais e sociais. Há diversos modos de ser jovem em nossa so ci edadee, portan to, não há apenas uma categoria teórica que possa dar conta dessadi versi dadedesi tu ações(Sposito, 1998). ${ }^{5}$

0 período de transição da juventude deve levar em consideração essa diversidade social, cultural, étnica, religiosa pois várias são as formas de entrada no mundo adulto e não é possível exigir que haja apenas uma. Do ponto de vista da exigência da modernidade, ou seja, de ver a juventude sempre associada ao futuro, há algo que não podemos negar: o jovem, hoje em dia, antes de ter projetos futuros, precisa ter ações para o presente. E esses projetos de futuro e as ações para o presente estão intimamente ligadas à enorme heterogeneidade dos segmentos juvenis existentes. 0 modo de se

4. Cabe ressaltar que as técnicas em grupo tiveram o objetivo de priorizar a relação entre os jovens, as imagens que faziam de si e dos outros, ou seja, a alteridade como ponto importante a ser explorado.

5. Conferência sobre J uventude, em maio de 1998, na Faculdade de Educação da UFMG. 
tornar adulto sofre as influências históricas por ter como base a ampla diversidade sociocultural na qual a juventude está inserida.

Neste estudo entende-se a categoria juventude como o momento da vida expresso no intervalo - cuja variação temporal é histórica entre a posse de condições de reprodução biológica (sexual) e a de condições de produção social (maturidade física e mental para o trabaIho), acompanhadas do reconhecimento social de sua habilitação plena para o desempenho dessas atividades na vida adulta.

Ao discutir a violência, Debarbieux (1998) associa a juventude à incivilidade e destaca a desorganização da ordem, a introdução do caos e a perda de sentido/de compreensão. Ao relacioná-la com essa incivilidade, ele acaba por apon tartam béma desorganização do mun do da escola, ou seja, a crise de sentidos pelo qual pas sa essa instituição. Nessa perspectiva, 0 autor "denuncia" o fracasso das escolas em cumprir as promessas de integração social, uma vez que a inserção dos jovens no mercado de trabalho é problemática: "É bem possívelqueaincivilidade de certos jovens seja uma incivilidade reativa à expressão de um amor decepcionado com uma escola incapaz de cumprir suas promessas de in serção" (Debarbieux, 1998, p.13).

Neste estudo foi possível explorar a violência que era vivenciada pelos jovens em seus locais de moradia para se entender como esta vivência poderia estar interferindo na dinâmica escolar. Assim, foi analisada como a violência vivenciada no local de moradia se relacionava com a construção da identidade dos jovens, por meio da interpretação das ações dos alunos, bem como das significações que eles atribuíam aos fenômenos sociais.

O universo da Vila da Luz na voz e na vez de seus jovens moradores

Os jovens (de ambos os sexos) da Vila da Luz, que foram ouvidos nesta pesquisa, tinham entre 14 e 19 anos. Todos eles mostraram ter clareza da situação de violência vivenciada na Vila e tentaram explicar os motivos pelos quais isso se dava: uns diziam que a Vila da Luz vivia em guerra com o Conjunto $A B C$ por questões de drogas, ou seja, pela disputa de pontos de vendas, etc; outros falavam que os moradores do Conjunto $A B C$ eram "pessoas malandras", que não queriam saber de nada e que, ten do chegado depo is, não sesubmetiam àsregrasan teriormen teco lo cadasporaqueles que "man dam no pedaço"; " outros diziamque tudo começou por causa da morte de um rapaz que foi roubado após ter decidido abandonar o vício, deixando, portanto, de adquirir drogas dos malandros do Conjunto ABC. Outros diziam que os moradores do Conjunto $A B C$ são pes so as que pegam asou tras "por sacanagem, sem motivos", o que, com razão, os deixava mais apavorados.

Questões importantes começam a ser construídas nesse percurso de compreensão da problemática da vivência da violência e da construção de identidade dos jovens: como esses jovens podem se defender, se nem os inocentes são poupados? Como saber quem sobreviverá, se há mortes sem motivos?

A realidade descrita pelos jovens parece indicar que eles necessitam de estratégias que os protejam, de um certo anonimato como medida de segurança na Vila da Luz. Eles não podem se envolver em confusões, e quanto menos eles forem vistos, melhor. Ao mesmo tempo, há relatos que nos apontam para a necessidade que eles têm de serem reconhecidos pelo grupo de moradores da Vila da Luz e da região, que inclui o Conjunto $A B C$. Em alguns momentos, eles dizem que precisam ser

6. "No original: "Il est bien possible que l'incivilité de certains jeunes soit une incivilité réactive, l'expression d'un amour déçu pour une école incapable de tenir ses promesses d'insertion (...)". Trad. da autora.

7. Essa expressão é dos meninos da Vila da Luz. Parece que é comum existir alguém que mande no pedaço. Eles convivem com isso, com alguém que deve ser respeitado por ser aquele que "manda no pedaço". 
conhecidos e reconhecidos como moradores do bairro, que isso Ihes dá segurança para, por exemplo, entrarem e saírem da Vila da Luz.

Assim a ambigüidade, reconhecimento/anonimato, parece fazer parte importante da problemática vivenciada por esses jovens. Em certas ocasiões, ser reconhecido é o que traz a segurança e, em outras, é o que gera insegurança e medo. Não ser anônimo pode ser bom (po dem an darpelaVila da Luz, li vremente, seguros e protegidos contra a discriminação). Quando anônimos, podem correr risco de vida, pois ninguém sabe quem eles são ou de onde vieram, o que pode ser ameaçador.

Masa am bi güi da denão ter mi na com essa divisão ou separação, pois veremos oportunamen teque, às vezes, ser reconheci do como morador da Vila da Luz traz ganhos para o jovem, propiciando-Ihe respeito, pelo menos na escola. Isso Ihe dá uma iden ti dadedeau to ridade, de temido, de valente e de "mais vivido". Além disso, é bom lembrar que, por ser tratar de ambigüidade, os dois sentimentos estão sempre presentes, ou seja, eles continuam existindo mesmo quando um deles não está explícito.

Além disso, o fato de existirem casos de pessoas inocen tesqueforamassassinadas, dei xa os jovens em situação de alerta. Afinal, se a inocência não garante a vida, o que a garante? Ino cente, na Vila da Luz, é morto por engano, ou seja, eles "pegam" a pessoa errada, pessoas que não são do tráfico. A ausência de motivos claros, que expliquem as mortes violentas, deixa os jovens em total insegurança e fragilidade. Não há controle e, obviamente, isso traz conseqüências para a construção da identidade. É como se eles se perguntassem a todo momento: essa pessoa morreu por quê? Ela era culpado, traficante ou foi morta por engano? Como posso me proteger para não ser confundido? É melhor ser anônimo ou ser reconhecido por todos? Se sou anônimo posso mor rer por en ga no (afinal, elesnão sa bem quem eu sou), mas se sou reconhecido também não tenho a garantia de não ser morto (pois também matam por engano).
Os sentimentos de insegurança e incerteza parecem criar um outro: o medo. Morar na Vila da Luz, sem sombra de dúvida, afeta significativamente a vida daqueles jovens. A vivência da violência no local de moradia desperta sentimentos que, en redados com os elementos integrantes de identidade, se tornam, também, elementos importantes na sua cons tituição. As identidades são construídas por meio de crises, no sentido eriksoniano, o que, portanto, significa que o jovem viverá momentos de ambivalência de sentimentos: medo e co ra gem, por exem plo. Deacor do com as passagens pelas crises previstas nesse processo, o jovem vai fazendo escolhas, retomando pontos de sua história, significando situações acontecidas anteriormente, etc. Como a juventude é uma fase em que há perdas (inevitáveis), por exemplo, do corpo infantil, o medo pode aparecer de forma imaginária, como uma proteção: até que se tenha certeza, é melhor temer e ficar a distância.

Da mesma maneira que o jovem oscila entre ser reconhecido e ser anônimo, ele tam bém oscila com relação a se expor ou retrair-se. Dizer sobre o que acontece lá na vila pode comprometê-los muito, pois podem ser "cobrados" por isso depois. Assim, omitem as si tuaçõesenão seex põem com facilidade.Um jovem relata que, quando eles vêem os moradores do Conjunto $A B C$, precisamcorrer. Mas, ao mesmo tempo, temem tomar essa atitude, afinal, aquele que corre é porque tem alguma coisa a temer. A situação é extremamenteangustiante: pois se ficam parados, podem ser baleados: se correm, podem indicar que devem alguma coisa e, também, ser baleados. 0 que fazer? Estaéa per gun ta que nor teia o co tidiano do jovem morador da Vila da Luz.

8. Expressão utilizada por um dos entrevistados, morador de um outro bairro. Ser "mais vivido" é, de certa forma, ser mais esperto, ter vivenciado mais situações, que the permitiram ser mais "vivido", menos ingênuo. 
Ao pensar na modernidade tardia podemos, segundo Giddens (1991), considerar que temos de construir nosso projeto reflexivo do self, ${ }^{9}$ diariamente, ou seja, optar, fazer escoIhas. Se assim é, como fica essa característica damo dernidadetardia ${ }^{10}$ (esco Iha diária)na vida de um jovem que já tem, nessa fase de sua vida, de lidar com tantas escolhas, dúvidas e inseguranças? Não seria para o jovem da Vila da Luz uma grande tarefa essa, de construir seu projeto reflexivo tendo questões tão sérias, de sobrevivência, para serem escolhidas a cada momento? Não seria isso cruel demais, pelo menos para a juventude aqui pesquisada, inserida na modernidade tardia?

Dando continuidade à vi vên cia dasam bigüidades dos jovens, temosa questão da sin gularidade: ser mais um ou ser um qualquer/ser singular ou ser diferenciado. Faz parte da juventude esse movimento de buscar, nos grupos, o reconhecimento de uma identidade que faça com que o jovem se sinta pertencente a eles. No entanto, tal movimento também é am bíguo, pois, ao mesmo tempo, o jovem quer ser reconhecido também como um sujeitosingular, diferente dos demais e busca esta auto-afirmação. 0 fato de estar em grupo, pode, àsvezes, ser amea ça dor. Afi nal, no gru po to dos parecem ser quase "iguais" (até pelo próprio jeito de se vestir, andar, falar, etc.) e, portanto, podem ser con fun di dosuns com osou tros, inocentes ou não. Mais uma vez vemos a necessidade de contextualizar de qual juventude estamos falando, pois, talvez com jovens que possuam outras vivências, o "andar em grupo" seja mais seguro se comparado com o "andar em grupo" para os jovens dessa pesquisa.

Os jovens procuram referenciais para minimizar os sentimentos de desamparo que sentem, mas, no entanto, nem sempre os encontram. Vemos que uma das maneiras pode ser exatamente o comportamento que eles têm apresentado nas escolas: agressivos e ou "fechados" para o diálogo. As dúvidas com as quais eles se deparam, diariamente, são substi- tuídas por atos impulsivos, atitudes grupais irracionais ou negações.

É espantoso ouvir os jovens contarem como essa vivência da vi o lên cia na Vila da Luz modificou suas vidas, seus cotidianos, seus pensamentos e até suas estratégias para se protegerem. Algumas atitudes podem nos parecer exóticas ou impossíveis, mas naquela realidade é questão de sobrevivência.

0 direito de ir e vir, sem dúvida, alimenta a autonomia tão necessária para o desenvolvimento do jovem. Mas o jovem da Vila da Luz não o possui. A falta de opção imposta para se obter um mínimo de seguran ça,certamente esbarra na sua formação, uma vez que, por excelência, o jovem está em uma fase na qual "fazer escolhas" é criar e fortalecer identidades.

Existe uma ânsia de locomoção que é expressada por um "ir em frente" e que também aparece na participação dos jovens em passeatas, movimentos de grupos de jovens, etc. Além disso, a sociedade oferece ao jovem possibilidades para que ele possa exercer essa ânsia de locomoção: esportes, danças, etc. Essa característica da juventude faz parte da construção da identidade e é essencial para que o jovem consiga estabelecer a sua identidade e seu estilo.

A sociabilidade desses jovens parece não ter conseguido, ainda, driblar as dificuldades impostas pelo seu local de moradia. Se há uma socialização, como aponta Sposito (1994), que vem nascendo no mundo da rua, nas esquinas e pontos de encontro, onde os jovens desenvolvem suas relações de amizade

9. "O projeto reflexivo do self consiste na manutenção de narrativas biográficas coerentes ainda que continuamente revistas e ocorre no contexto da escolha múltipla filtrada através dos sistemas abstratos" (Giddens, 1991, p. 4).

10. "A modernidade é uma ordem pós-tradicional, na qual a pergunta 'como hei de viver?' tem de ser respondida através de decisões diárias acerca de como comportar-se, o que vestir e o que comer - e muitas outras coisas, bem como interpretada no desenrolar temporal da auto-identidade" (Giddens, 1991,p.13). 
e lazer, exatamente por enfrentarem os mecanismos da violência urbana, essa socialização não pôde ser observada nos jovens pesquisados. Segundo ela, nesses espaços da rua os jovens buscariam construir suas identidades coletivas e as modalidades de sociabilidade. Percebe-se que os jovens pesquisados ainda não se envolveram em ações coletivas, não tornaram-se atores sociais atuantes. 0 espaço urbano da Vila da Luz não é visto como um espaço que foi reapropriado por aqueles jovens com possibilidade de se tornar um novo espaço parano vasredes deso ciabilidades. Nessesentido, o fato de não poderem sair de casa só dificulta a articulação desses jovens, que poderiam buscar nova sociabilidade, apesar do lo cal onde moram.

Erikson (1971) fala de etapas de evolução, cada uma delas correspondendo a uma aquisição que 0 indivíduo deve realizar em sua interação com o mundo. A organização da iden ti da deéa eta pa cen tral pro posta por elena evolução do ciclo humano. É um momento de síntese, de transformação de identificações em identidade e de interação original com o mundo (Fiori,1981).

Assim, chegar na juventude e não poder fazer escolhas poderá comprometer a afirmação de sua identidade, crise psicossocial desse momento, segundo Erikson. É como se houvesse uma regressão do ponto de vista emocional pois esse é o momento, por excelência, em que o jovem precisa acreditar que é capaz de ser al guém no mundo.

É impossivel falar de identidade sem falar de sociabilidades. A identidade pode ser entendi da como um con jun to derepresen ta çõesquea sociedade e os indivíduos constroem sobre algo que dá unidade a uma experiência humana, múltipla, facetada, tanto no plano psíquico como no plano social (Marques,1997). Tanto as juventudes quanto as identidades são construídas de formas diversas, segundo as diferentes sociedades, o lugar social que o sujeito ocupa, os conjuntos de valores, idéias e normas, etc., que vão formarseu instru men to deleitu rapara a interpretaçãodo mundo. Assim, cada sujeito, de acor do com seu con tex to só cio-histórico ea partir desses referenciais, vai organizando a sua percep ção da reali dade. “Todaiden ti da deé socialmente construída no plano simbólico da cultura" (Marques,1997, p.67).

Sabemos também que possuímos, todos, várias identidades: a identidade pessoal, a identidade familiar, a identidade social, etc. Assim também é com o jovem: ele possui uma identidade na família, na escola, na galera, no futebol, no trabalho, no lo cal demo ra dia, etc. Como há muitas identidades, precisamospensar como o jovem se relaciona com a família, na escola, no local de moradia, etc., para pen sar a sua identidade. Pela pesquisa, em todas essas áreas, o jovem da Vila da Luz ainda não tem como recompensar a sociabilidade comprometida na Vila.

A vila desce ${ }^{11}$ para a escola Professora Inês Gonçalves - a dinâmica dos encontros e as estratégias de convivências

Pensando nos alunos da Vila da Luz, so mos levados a considerar que eles lidam com algo que Ihes desagrada (morar na Vila da Luz), mas que, ao mesmo tempo, é algo que os protege (morar na Vila da Luz). Essa ambigüidade nos foi assinalada por alunos que moram em outros bairros. Ao descreverem os colegas da Vila da Luz, eles sinalizam traços de violência nos comportamentos de seus colegas da vila; entretanto, entendem que esses traços, embora marginalizem os alunos de Vila da Luz, são usados por estes, convenientemente, para garantir sua própria sobrevivência ou autoproteção na escola.

A sociabilidade dos jovens da Vila da Luz, marcada pela violência, se reproduz,

11. Termo utilizado pelos jovens da Vila da Luz para referirem-se ao fato de irem para a escola. 
portanto, tam bém no in teri orda es co la. Namedida em que a escola não representa mais uma fortaleza de "sossego e tranqüilidade", ela pode, como vem sendo, ser freqüentada por pessoas que não fazem parte de sua dinâmica interna. Nessa perspectiva, ela deixa de ser um fator de proteção, para se constituir em fator de risco.

As representações que os outros alunos constroem de seus co legas da Vila da Luz oferecem-nos um quadro de perplexidades, pois nele vislumbra-se um tipo de solidariedade grupal que se constitui por e na violência.

Movidos pelo medo e pelas ameaças, alguns alunos receiam que seus colegas da Vila sejam eles mesmos os "malandros" da Vila, "os que matam"; outros, entretanto, receiam que eles sejam amigos dos "malandros" da Vila, estes, por sua vez, podendo ser convocados a qualquer momento, para dar uma "mãozinha" nasbri gas do mésticas, na es co la: estáforma da, assim, numa espécie de corporação a serviço da vi o lên cia; corpo ração esta que, segun do osalunos de outros bairros, tem sido utilizada para ameaçar os outros.

Chama-nos a aten ção, nos relatos, o fato de que os jovens de outros bairros interpretam a violência praticada pelos alunos da Vila da Luz como uma "violên ciagratuita", sem motivo real, pautada em motivos inventados: "é uma desculpa" ou "uma oportunidade para cair numa briga", dizem eles.

É interessante observar que os jovens relatores identificam a "briga" quase como uma necessidade do "outro", um impulso que tem de cumprir sua trajetória natural, com ou sem motivo consciente. Nesse sentido, tal visão coincide, em parte, com alguns pressupostos psicanalíticos, dentre os quais aquele que entende os impulsos como algo que existe na estrutura psíquica humana, não necessitando de nenhuma razão externa para manifestar-se.

Pa rece-nosquea distin ção en tremo ti vos e razão nos ajuda a compreender melhor a observação feita pelos alunos de outros bairros.
Basta lembrar que, para Gid dens (1997), as razões se diferenciam dos motivos, porque elas formam uma característica constante de ações, ou seja, se quisermos compreender como os sujeitos monitoram a própria ação reflexivamente, devemos entender as razões que os fazem agir desta ou daquela maneira. Já os motivos, como nos diz o autor, "devem ser entendidos como um 'estado sentimental' subjacente do indivíduo, envolvendo formas inconscientesbem como afliçõesein citamentos experimentados de forma mais consciente" ( Giddens, 1997, p.59).

A resposta a essa questão tem de ser buscada, também, no plano da cultura. Ela tem nos oferecido categorias cooperantes ou alternativas que nos ajudam a entender 0 fenômeno em consideração.

Vejamos: o jovem pode criar, por exemplo, um motivo que justifique seu ato de violência em relação a seus colegas porque sabe que será julgado por suas ações. Uma violência sem motivos plausíveis é "muito pior" do que uma outra justificada, embora ambas produzam o mesmo ef eito para a sua vítima. Mas ele pode, também, justificar seu ato inventando um motivo banalíssimo, conforme os que fo ram relatados, porqueelenão con segueex pressar, no ní vel dalin gua gem discursiva, os motivos internos que o levam a agir daquela maneira.

Enriquez (1990), ao estudar a natureza dos vínculos sociais, demonstra o quanto a violência pode significar uma forma de 0 indivíduo proteger-se contra uma possível desintegração do próprio ego. Ele reage violentamente todas as vezes em que se sente impotente e muito frágil ante as ameaças externas de perda de sua integridade.

No caso do jo vem citado aci ma, seriadizer que, para proteger seu ego de ameaças constantes de desintegração psíquica, ele, morador da Vila da Luz, inventa um motivo para exprimir sua "agressão" autoprotetora. Dito de outra forma, age com violência, não 
porque seja destemido, e sim porque é frágil e desprotegido. Sua segurança ontológica ${ }^{12}$ está profundamente ameaçada; entretanto esse é um dado que permanece oculto ou, pelo menos, não consegue ser traduzido em linguagem oral. Isso talvez explique porque sua violência em relação a outros alunos seja vista, por esses outros alunos, não como resultado de uma "in segurança psíquica", mas, sim, como afirmação de sua identidade.

Uma outra hipótese plausível ao uso da "violência gratuita" aponta para o fato de que nosso jovem pode agir dessa forma porque teme o diálogo. Nesse caso, estamos lidando com outra forma de se pensar os atos de violência. Está implícita, na hipótese acima, a idéia de que tais atos poderiam ser controlados e/ou eliminados, se pudéssemos fazer com que os motivos que os tornam violentos fossem convertidos, ou seja, traduzidosem linguagem racio nal, com perguntas e respostas, com réplicas, com concordâncias, dissensos, enfim, com diálogos.

Como o conflito só se manifesta quando há diversidade de idéias, de opiniões e de práticas, pode-se dizer que ele funciona como espécie de "animador cultural", estimulando o debate e o diálogo entre os indivíduos que compartilham, entre si, um mesmo espaço para realizar algum tipo de atividade. É assim que a so lu ção decon flitospo deria serealizarnatu ralmen tena "mesa denego ci a ções" (Velho, 1986).

A escola poderia vir a ser o local do aprendizado dessa negociação. Como não tem, em sua maioria, cumprido essa função, os conflitos têm se exacerbado a ponto de ficarem inegociáveis, dando-se, assim, espaço à violência explícita. Já que nesse jogo de construção identitária corremos o risco de encontrar identidades estigmatizadas, como, por exemplo, entre os meninos da Vila, não deveríamos estar pensando se existe alguma forma de neutralizá-las no ambiente escolar? Poderia a escola interferir em representações tão negativas ?

Vários aspectos precisam ser analisados. Como exemplo, poderíamos entender o gesto de hostilidade em relação ao "olhar-na-carado-outro", como um ato de incivilidade, de descortesia. Goffman (1992) mostra que a interação em lugares públicos cria regras para os olhares: em geral o que se observa é uma espécie de "indiferença civil" quando se está entre estranhos. Ora, sabemos que não é aceitável o fato de "olhar no olho do outro" e muito menos "encarar com insistência" alguém com quem não se tem muitain timidade.

Entretanto, o caso em questão pode indicar algo para além da descortesia. 0 olhar para o outro pode despertar estigmas, sobretudo se esse outro for considerado superior, esnobe ou "boy", tal como os meninos da Vila da Luz consideram os alunos de outros bairros.

Do ponto de vista psicanalítico, podemos refletir que olhar pode indicar uma encruzilhada para onde convergem diferentes fantasias inconscientes, de natureza sexual e agressiva. Há uma dimensão angustiante do olhar/ser ol ha do. 0 ato de ver está a serviço de um controle e de uma discriminação (Mezan, 1989). 0 imaginário pode, mais uma vez, fazer aqui sua aparição, uma vez que qualquer olhar dirigido já vem carregado de significados pejorativos e de exclusão. Para os meninos da Vila da Luz, esses olhares podem significar um ato que deflagra suas diversidades, além de se sentirem julgados e talvez condenados à exclusão ou à marginalidade. É um olhar que ameaça e confirma uma identi-

12. Erikson (1971) nomeou uma série de estágios de desenvolvimento da personalidade que vai da infância até a idade adulta. Em cada um desses estágios a criança vai superando um obstáculo para que se sinta capaz de enfrentar o próximo. Ele comenta: que a primeira realização social da criança é, portanto, sua disposição de perder a mãe de vista sem que isso lhe cause angústia ou raivas desmedidas, pelo fato de a mãe ter se tornado tanto uma certeza interna quanto uma previsibilidade externa. Dito de outra forma: é desde muito cedo que a criança vai adquirindo "confiança" que significa para ela também segurança. Inspirando-se nessas reflexões, Giddens procura trilhar um caminho em busca do que ele denomina de "segurança ontológica". Para ele, a consciência prática, as rotinas e a confiança são possibilitadoras dessa segurança (1997). 
dade que eles não suportam, mas que, também, Ihes serve como proteção.

No relato de um dos jovens, pode-se observar que a questão do "olhar-na-cara-do-outro" aparece como motivo suficiente para uma briga. Ele mesmo, embora morador da Vila, reconhece que as brigas têm motivos fúteis. Chama-nos a atenção o fato de ele indicar que al gunstipos depro blemaspo deriamser conversados, ou seja, resolvidos por meio do diálogo, mas no entanto, viram briga. Como o próprio jovem nos remete à dimensão comunicativa como uma forma de resolução de conflitos pessoais, imaginamos que essa dimensão poderia ser mais explorada pela escola.

As estratégias de convivência, na escola, dos jovens que moram na Vila da Luz

Como a sociabilidade pressupõe um jogo com regras, mais ou menos definidas, é comum, na investigação dos processos que a compõem, ouvir os sujeitos falarem da forma que usam essasregraspara con seguiral gum nível de aceitação social.

Enganam-se aqueles que acreditam serem os sujeitos completamente desprovidos de estratégias de sociabilidade capazes de produzir um mínimo de inserções, apesar das hostilidades e estigmas que pesam em todo processo de exclusão social. Nesse caso, não discordar significa agirpreven tivamen te, em bo ra adiscussão ea discordância sejam fundamentais para a construção da identidade juvenil. Muitas formas, sutis, de defesa do self contra os estigmas e discriminações foram reveladas nas entrevistas. Dentre elas, destaca-se a omissão do local de moradia.

Áreas carentes são associadas à violência e, por isso, existe um medo generalizado. No caso da Vila da Luz, parece que a violênciaatingiu ín di cesmu i to eleva dos, sen do estaVila alvo de ações de diversos órgãos da prefeitura de Belo Horizonte. As pessoas da região temem a Vila da Luz, especialmente. Há um certo estigma que marca a referida Vila, pois além do alto índice de assassinatos que ocorrem no local, a brutalidade dos crimes, às vezes, assusta moradores e não-moradores. ${ }^{13}$

Esconder onde mora pode ser estratégico para se conseguir um(a) namorada(o), um em prego e, so bretu do, para não ser estig matizado. Decidir pela "ocultação" ou "mentir para não ser discriminado" tem profundasimplicações éticas. Nesses casos, fica claro 0 quanto 0 debate sobre a moral, enquanto constructo fundamental da formação da identidade, não pode se afastar da realidade sociocultural sobre a qual os sujeitos julgam os comportamentos alheios. Por exemplo, diante do relato de um jovem de 18 anos que se vê compelido a mentir sobre o local onde mora para evitar discriminação, como deveria sepor tar um pro fes sor? Como será que ele deveria orientar moralmente esse aluno?

A violência identificada ao local de moradia impede o trânsito de amigos e colegas. Os en con tros são res tri tos a áre as fora da Vila. A situação começa a ser compreendida, pois, quan to ma i ora vi o lên cia, ma i or seráo medo e menor será a satisfação com o bairro, a ligação com o lugar, o espírito de comunidade, a identificação comosou tros, a dispo nibilidade para ações coletivas e para a cooperação.

Os jovens da Vila, conscientes do medo que despertam em seus colegas, parecem ter aprendido a lidar com este estigma. Entretanto, necessitam deum esforço su plemen tarpara conquistar a confiança dos outros. Os sentimentos de injustiça e de estigmatização ficam muito claros: mesmo quando não têm culpa, eles são considerados os culpados: "tudo de ruim queacon tecena esco la, a cul pa énossa".

Vale ressaltar o peso da vergonha e da humilhação na formação da identidade dos

13. Não é incomum o relato de alguém que morreu com um número elevado de facadas ou tiros e até mesmo com atos de crueldades do tipo: arrancar os olhos, a língua, as unhas, pedaço da orelha, etc. Os jovens, ao falarem dos crimes que acontecem lá, sempre os relatam com essas características de barbárie. 
jovens. Elias (1990; 1994), em seu céle brees tudo sobreo processo civilizador, mostra-nos de que maneira muitos de nossos hábitos civilizadosfo ram in cu ti dos pormeio do sen ti men to de vergonha (gestos ou comportamentos) que sentíamos.

Giddens remete a vergonha diretamente para a auto-identidade: "a vergonha manifestada refere-se a sentimentos experimentados por uma criança quando é de algum modo humilhada por outra pessoa" (1997, p.61). 0 inverso da vergonha seria, segundo ele, o orgulho, a auto-estima: "a confiança na integridade e valor da narrativa de auto-integridade" (1997, p.42). Sendo assim, provocar a humilhação pública de uma criança, ou aqui, de um adolescente, é o mesmo que diminuir sua auto-estima, fazê-lo perder a confiança na integridade de sua auto-integridade. Em outros termos, é expô-lo e incitá-lo a agir com violência extrema para salvar seu "ego da desintegração psicológica".

A alteridade na construção da identidade é fundamental - a imagem que o outro faz do jovem pode in terferirnaconstrução daima gem que ele faz de si próprio. Mais uma vez a violência torna-se, mesmo indiretamente, el emento que participa na construção de identidades dos jovens, uma vez que essa violência interfere em elementos fundamentais para essa construção.

0 medo sentido pelos jovens moradores de outros bairros acaba interferindo na convivência dos alunos na escola. 0 sentimento de rejeição nem sempre é resolvido de maneira pacífica. A atitude mais usual é reagir com certa agressividade, que acaba criando um ciclo vici0so: a violência que acontece na Vila da Luz ameaça e amedronta os outros jovens na escola.

A violência que ocorre na escola tem várias interpretações: para os moradores de outros bairros, ela começa pelos meninos da Vila da Luz; estes afirmam que os outros meninos os provocam e os tratam mal. Assim, cada um tem suas explicações. Cabe entender como essa convivência está acontecendo e quais as estratégias eles têm usa do para, bem ou mal, estarem no mesmo local, todas as noites.

Confiança e segurança no cotidiano dos jovens da Vila da Luz

Os relatos dos jovens da Vila da Luz apontam para aquilo que consideramos central na formação de suas identidades: 0 sentimento de segurança capaz de ajudá-los a enfrentar as ansiedadesexisten ciaisno cotidiano. Como o referido sentimento é apresentado de forma muito restritiva, vale examinar, a seguir, o que leva aqueles jovens a nutrir tanta insegurança no seu dia-a-dia.

Comecemos, por exemplo, pela própria origem desse sentimento. Segundo Giddens (1997), os indivíduos desenvolvem estados de confiabilidade, na primeira infância, a partir das experiências com seus "educadores" (pais, tutores, etc.). Essa maneira de conceber a origem do senti men to desegu ran ça estáapo iada nas teorias dos psicanalistas D. Winnicott e E. Erikson, para os quais as crian çasestabelecem elos com seus educadores iniciais e aprendem a lidar com a ausência do outro sem ansiedade. Seguindo essa linha de raciocínio, "a confiança básica, desenvolvida através das atenções carinhosas dos encarregados de educação nos primeiros anos de vida, liga fatalmente a auto-identidade com os educadores iniciais". E ainda, "a mutualidade com os educadores iniciais (...) pressupõe uma sociabilidade base, prévia para qualquer diferenciação entre os dois" (Giddens, 1997, p.36).

Em termos teóricos, para o estudo da reação dos nossos jovens perante situações ameaçadoras, o que nos interessa analisar é a eficácia desse sentimento para eles. Teríamos condições de comentar alguma coisa a esse respeito?

Certamente nada podemos falar acerca da relação entre os jovens e os encarregados 
de sua educação na primeira infância. Mas há muito o que dizer sobre o sentimento de insegurança ou de pouca proteção em face de situações debilitantes com as quais eles têm se confrontado.

Comecemos pelo relato de uma entrevistada:

Há dois anos atrás eu gos ta va mu i to de sair com minhas amigas, gostava de namorar, adorava 0 pai da minha neném, gostava muito de ficar do lado dele, eu sentia que do lado dele eu tava protegida e tudo (...)

Eis aí um belo retrato de autoconfiança. Uma jovem de 16 anos, rodeada de amigas e apaixonada. Um amor protetor. Entre as amigas, ela destaca a irmã e uma outra jovem. ${ }^{14}$ Ambas são admiradas pela franqueza. Mastudo isso, esta auto-segurança, acabou. Hoje, diz ela, eu não sei te falar do meu jeito de ser... se você me perguntasse isso há...dois anos atrás eu sabia te responder, mas hoje eu não sei .

Há dois anos atrás ela engravidou; hoje, é mãe de uma menina. Em seu relato, fica claro que 0 pai de sua filha, aquele que a fazia se sentir protegida, não quis ficar com ela: quando eu precisei dele prá ficar comigo ele não quis (...) eu gostava muito dele. A gora eu gos to dele como pai dela (...) não acontece sexo, não acontece nada.

Ao perder seu amor protetor, ela reduz seu círculo de relações. Assim nos diz: mas hoje...o que tenho prá falar mesmo é da minha nenenzinha, da minha mãe e da minha irmã (...). Freqüento a Igreja Universal, minha mãe freqüenta, aí vou junto com ela.

A vida da jovem parecer ter mudado de rumo com a ruptura afetiva; entretanto, o núcleo básico de sua "confiança" foi reativado: a mãe e a irmã. Parece que esse núcleo a tem auxiliado a suportar as angústias do dia-a-dia. Esse casulo protetor permite a ela distanciar-se de atitudes que ferem a sua auto-identidade. Afirma com veemência:
Tudo que eu não gosto é traição, é a pessoa vim e eu pegar ela fa lan do de mim, odeio isso. Eu fico au to ri tá ria, sabe, eu não memudo, ${ }^{15} \mathrm{eu}$ começo a brigar, começo a falar alto...discutir...eu fico fora de mim.

A traição é uma atitude imperdoável, na sua fala. Para ela, isso deve ter um significado muito forte. Sentir-se traído é perder a confiança em alguém no qual foi depositada uma parcela importante da vida íntima. No caso dela, houve uma mu dan çadesuaau to-iden tidade:

As pessoas me acham um pouco esquisita, ah, porque eu não sou....aquela pessoa de chegar, con versar, de fi car brin can do, eu gos to deficar mais qui e ta no meu can to, eu e mi nha irmã, se a pessoa chega perto de mim prá conversar eu con ver so, ago ra se for prá mim sair prá con versar eu não consigo conversar não. Aí eles me vê, ah, esquisita prá caramba, não vê eu como uma pessoa normal. Mas acho que não tem nada a ver não, prá mim não.

Tudo indica, em seu relato, que a possibilidade de contato com o outro está bloqueado por um forte sentimento de traição. Ainda que o núcleo básico de sua confiança tenha sido restituído, ele tem funcionado mais como um casulo protetor do que um estímulo para novas relações.

Nos outros relatos, o núcleo familiar desaparece praticamente da referência da "confiança básica". Os amigos aparecem formando o grupo no qual os jovens se sentem parcialmente seguros.

Um ou tro jo vem diz quegos ta de sair no fim de semana com "os meninos da sala". Quase tudo que eu gosto, diz ele, meus amigos gostam. Isso eu acho legal. Eles gosta,

14. Esta amiga morreu em 1997, de meningite.

15. Pelo sentido da frase, no contexto, "não me mudo" é "não me calo". 
tipo assim, de músicas que eu gosto, sair nos lugares que eu gosto, é..., a minha idéia é a deles.

Nesse exemplo o "núcleo de confiança" está na escola: são seus colegas de sala. M esmo tendo alguns moradores da vila como ele, a escola é focalizada como o cenário dos encontros. Há também o valor dado ao trabalho: trabalhar prá mim é bão, não fico à toa. Salvo quando está com os amigos, ele prefere o sossego: Eu não sou muito de brincar, assim, de ficar zoando pela rua afora, ando mais é calado... calado no meu canto.

0 "núcleo familiar" está ausente em seu relato, mas suas relaçõesíntimas e de confiança são construídas no cotidiano escolar; ou seja, radicalizando-se a idéia de que alunos são, antes de mais nada, sujeitos socioculturais, capazes de dar sentido e significado às suas ações, podemos verificar qual o significado que esse jovem morador da Vila da Luz tem dado à escola. Esta pode se consti tu ir em um espaço de desenvolvimento de afetividades, ajudando a construir relações de empatia, a reconhecer no outro virtudes a serem cultivadas. Nos outros, diz ele, admiro a beleza, sabe, o jeito de tratar, a edu ca ção, o respei to, admi ro mu i to isso. Não nega seu cotidiano violento. Afirma: já vi muita violência. Para se defen der, pen sou em comprar um revólver. Diz ele: andei armado muito tempo, tinha um pouco de bosta na cabeça, mas eu nunca pensei de fazer covardia com os outros, assim não, eu sempre fui mais calmo. Curiosa relação entre "andar armado" e "ser calmo". Aliás, foi o "andar armado" que nos motivou a realizar a presente enquete. ${ }^{16}$ Como se pode ver no relato desse jovem, a arma aparece para protegê-lo da violência. É uma resposta absolutamente individual a um fenômeno social mais amplo. Os amigos e a relação afetiva tiveram um papel importante na reavaliação que ele faz do próprio cotidiano. Entretanto, não descarta o esforço pessoal: Prá uma pessoa ser feliz assim, só basta ela ter.. tipo assim, cabeça, não se envolver muito.
A relação de confiança, no atual contexto cultural, exige uma certa mutualidade, como nos lembra Giddens (1997), ou seja, a confiança não pode mais, por definição, assentar-se em critérios exteriores à relação em si - tais como critérios de parentesco, dever social ou obrigação tradicional. Para consolidar-se, a confiança só pode ser mobilizada mediante um processo de revelação mútua entre as pessoas. Embora ainda haja muitos critérios baseados em relações familiares ou em critérios tradicionais do tipo religioso, há critérios intrínsecos relacionados ao prazer mútuo.

Esboçadas as idéias que nos ajudam a compreender a origem do sentimento de confiança quanto suas características básicas, vale examinar as razões que os levam a sentir falta de segurança.

Diferentemente do que se pode imaginar, a insegurança não é originária da ansiedade ou de sentimentos difusos e imprecisos. Ao contrário, ela tem uma causa muito concreta: a violência, que gera medo. É daí que vem a perda de referência; a insegurança é alimentada por diversos fatores. A ausência de motivos para os assassinatos ou os assassinatos por engano geram uma insegurança que se torna totalmente persecutória: quem será poupado? Quem será o "escolhido"? 0 quepreci so fazer para que eu não seja a próxima vítima?

Achar os motivos para as mortes e explicar tamanha violência parece trazer aos jovens pesquisados um grau mínimo de

16. Quando a diretora da escola foi entrevistada ela relatou que alunos da vila estavam indo armados e era exatamente isso que preocupava a escola naquele momento. 0 desconhecimento sobre 0 que fazer nesse caso e também a explicitação desse fato é que determinou a escolha dessa escola para a realização da pesquisa, como dito anteriormente. A Vila da Luz, nesse momento, passou a ser uma fonte importante para a coleta de dados, especialmente por meio da fala dos jovens moradores de lá. Ou seja, era preciso investigar por qual motivo os alunos moradores da Vila da Luz "precisavam" ir armados para a escola e seus desdobramentos no interior e na dinâmica da mesma. 
segurança para viverem. A relação entre merecimento/morte/violência parece servir ao mesmo propósito, ou seja, quem faz algo de errado merece morrer - isso parece tranqüilizá-los.

A experiência da violência os faz questionar suas vidas, suas amizades, seus sentimentos, suas estratégias de segurança: para os jovens da Vila da Luz a construção reflexiva do self é feita com muito empenho e a todo momento.

Em climadetantain segu ran ça, a confiança surge como categoria a ser investigada bem com sua relação com o local de moradia. Parece que não morar na Vila faz com que a confiança tenha outras configurações. 0 local perigoso da moradia interfere na aquisição ou não da confiança nos outros e pelos outros, 0 que traz consequências nas aquisições e manutenções das amizades. Assim, a "mãe" e "Deus" aparecerem como os únicos dignos de confiança, com raras exceções.

Um jovem toca no cerne do problema da confiança, a saber: o seu potencial de perseverança, mesmo quando o outro está ausente. No conceito de segurança básica, a confiança só se estabelece quando, na ausência dos educadoresini cia is, a cri an ça con se gue con tro lara an siedade, ou seja, quando a confiança se articula comafidelidade: como con fiaremal guém que, na sua fren tepareceami go, maslon getorna-se seu "inimigo" e coloca sua vida em risco?

Para outros, a confiança está relacionada à vivência estritamente pessoal: "eu" e " ele" e mais ninguém: $A h$, tem um só colega meu que eu confio nele né, porque nós anda, só nós que anda junto. Nele eu confio.

Além desse exemplo, o mesmo jovem fala da dificuldade em confiar em alguém por causa de suas experiências anteriores. Ele trabalhou para uma pessoa e não recebeu o salário. Mas 0 medo que faz parte de sua vida, que o acompanha no seu dia-a-dia, o impediu de exercer sua cidadania e cobrar do patrão.

Segundo Giddens (1997), o self não é passivo e determinado por influências exter- nas; ao contrário, ao forjarem suas identidades, independente do caráter reduzido dos seus contextos de ação, os indivíduos contribuem para e promovem diretamente influências sociais com conseqüências e implicações globais. Em outros termos, o self tem de ser construído reflexivamente e no meio de uma confusa diversidade de opções e possibilidades. No mundo da modernidade tardia, nos diz ainda Giddens, a identidade não está dada, pronta, acabada. Os sujeitos influenciam e são influenciados pelos contextos sociais, locais e globais. Há uma diversidade de opções e possibilidades nas quais o sujeito precisa construir seu self, reflexivamente.

Estratégias singulares na busca da segurança e suas possíveis contribuições no entendimento da violência como elemento constituinte da identidade

Parece não haver muitas regras comuns para se evitar a violência e se proteger dela na Vila. ${ }^{17}$ Cada um, de acordo com suasvi vên ci as, busca suas próprias estratégias: a da "boa vizinhança", citada por alguns jovens, pode parecer boa, mas cabe-nos perguntar qual seu ef eito para a construção de identidade do jovem. Não dizer o que pensa, não poder posicionar-se de acordo com os princípios que julga corretos, éti cos, sem dú vida, in terferena construção da identidadejuvenil. E, se quisermos saber qual é o motivo pelo qual ele não pode ser autêntico, questionador, etc., vemos que a violência parece estar por trás dos com portamentos assim descritos por eles: é preciso ter "jogo de cintura" , não pode ser desconhecido de todos, mas também não pode ser íntimo de ninguém, não é seguro

17. Parece que a "lei do silêncio" também impera na Vila da Luz como em tantas outras. Não ver nada, não saber de nada ainda parece trazer certa segurança ou, no mínimo, não procurar confusão, como eles dizem. 
"embolar no meio deles", mas também é preciso cumprimentar, etc.

0 ambiente seguro, calmo e tranqüilo que nós tanto prezamos e sabemos importante para o crescimento do jovem e para a construção de sua identidade, também é alterado na Vila da Luz.

A casa, lugar de aconchego, de proteção cede ao clima da violência. Seus moradores co meçam a questionar sua eficácia: mudam-se camas de lugares, balas entram pela janela... Qual é, então, o lugar da segurança?

As ambigüidades vivenciadas pelos jovens da Vila da Luz apareceram em vários momentos, na fala de muitos deles. A sociabilidade parece ser ameaçada a todo instante por uma frase, imaginária, vinda de seus colegas e, de modo geral, pela comunidade, assim resumida: diga-me de onde vens que te direi quem és.

Infelizmente, esses jovensain da precisam provar que, apesar de serem moradores da referida vila, são jovens e merecem respeito, apesar das diferenças. $E$, para isso, pagam um preço às vezes alto demais para pessoas jovens demais. Temos a expectativa de que a escola possa participar cada vez mais unindo "diversidade" e "respeito" e incentivando o diálogo entre os alunos como uma das formas de romper com a violência. A escola é um local onde os jovens brigam, criticam, depredam, mas, apesar disso, desejam, e sobretudo vão até lá, no mínimo, para se encontrarem. E, nós, não podemos nos esquecer disso.

\section{Considerações fina is}

Embora muitas questões tenham sido levantadas e nem todas tenham sido respondidas, ainda cabem algumas considerações.

A hipótese (inicial) de os alunos da Vila da Luz serem os autores da violência na escola precisou ser verificada ao longo de toda a pesquisa, partindo da fala desses alunos e também de seus colegas de outros bairros.
A realidade do seu local de moradia, a Vila da Luz, revelou-nos um alto índice de violênciarelatado pelos alunos, com destaque para assassinatoscom requintes de crueldade. Os jovens mostraram como é possível e o que precisavam fazer para sobreviverem. As estratégias, as mais variadas possíveis, eram o que os permitiam manter-se vivos e não perderem a esperança de que tudo po diamu dar. Quan to maior a violência, maior parecia ser a sua banalização para seus moradores.

Vimos, neste trabalho, que os jovens que se sentem vítimas na Vila da Luz chegam à escola e vivem o estigma do "malandro", embora não seja exatamente isso que eles desejem.

Ser da vila pa recetrazervan tagensedesvantagens. Essa ambigüidade é vivida intensamente no espaço escolar, desembocando, às vezes, em situações de violência entre os alunos (brigas de correntes, espancamentos, etc.) ou em atos de violência contra o patrimônio (bombas no banheiro, fogo nas latas de lixo, etc.). Essas brigas acontecem muito mais para mostrar o que eles são capazes de fazer para amedrontar colegas e professores. Não se trata de uma violência escolar no sentido de uma reação à instituição escolar. Os atos de violência servem para demarcar espaços de poder.

A presente pesquisa mostrou também quea vi o lên cia que ocor re em casa ou no ba ir ro pode afetar a construção da identidade. Nasen tre vistascom osjo vens, foi possí vel observar uma certa dificuldade, sobretudo dos que vinham da Vila da Luz, de se orgulhar do local onde moram e de ter uma identificação com os moradores de lá.

A alta rotatividade dos moradores da Vila da Luz, na fala dos jovens, pode, de certa forma, aumentar a desconfiança nas pessoas, prejudicando, assim, o contato entre elas e, consequentemente, a construção das identidades entre eles.

A banalização da violência é preocupante, pois não podemos ver com naturalidade 
que um jovem acredite que um ato de violência seja somente aquele que envolva revólver e morte.

Nesse clima de tensão e de terror, com traficantes e pessoas morrendo sem saber os reais motivos, é esperado que haja uma diminuição ou um empobrecimento de modelos, sejam esses familiares, sociais, profissionais e de ascensão social.

Mas há algo que não podemos negar: os jovens da Vila da Luz, "descem" para a escola. Isto nos mostra que esta última ainda é um local público que favorece encontros entre eles.

Sem a participação desses jovens, nós jamais sairíamos do senso comum. Os jovens da Vila da Luz ajudaram-nos a compreender uma dinâmica de estigmatização na escola e os significados de seus conflitos. Graças a eles pu demos construir novas referências, neste trabaIho, sobre a construção de identidadeen tre eles e também sobre as relações de confiança, fundamentais nessa construção.

Cabe ressal tarqueem bo ra tenham sido citados vários teóricos que enxergam a juventude como um período em que há conflitos em casa e no qual os jovens preferem andar em grupos, os dados empíricos dessa pesquisa não apontaram para isso. Os jovens pesquisados da Vila da Luz ainda têm a casa e os pais como referências relativamente seguras e preferenciais, talvez por já viverem tantos outros conflitos e inseguranças fora de casa. Com relação ao fato de os jovens da Vila da Luz, às vezes, preferirem estar sozinhos a estar em grupos, talvez se deva fato de que, esses jovens vivam, como já citado an teriormente, uma ambigüidade com relação à vivência grupal: ora sentem-se seguros, ora correm risco de vida, o que pode não ocorrer com um outro jovem que vive em um outro contexto sociocultural,no qual viver em grupo é seguro e satisfatório.

Isso nos leva a pen sarquenão po demos tomar as teorias como válidas em qualquer contexto. Cabe a nós, pesquisadores, buscar discernir dentre as teorias em vigor aquelas que nos ajudam a entender a realidade que estudamos.

Sobre os jo vens da Vila da Luz, o que temos a dizer é que não há vítimas nem vilões. Não há malandros que, aqui, viram heróis. 0 que cabe fazer talvez seja abrir possibilidades para que eles possam atuar como sujeitos de sua história, para que possam participar de projetos que valorizem e respeitem sua diversidade e incentivem a postura de diálogo aci ma de qualquer coisa.

\section{Referências bibliográficas}

ABRAMO, H. W. Considerações sobrea te matização social dajuventude Brasil. Revis taBrasileiradeEducação.J uventude e Contemporaneidade, n. 5-6, 1997. Número especial.

ABRAMOVAY, M. etal. Gangues, ga le ras, chega dos erap pers: ju ventude, vio lência ecida dania nas cidades dape rife riade Brasília. Rio de J aneiro: Garamond, 1999.

AMORETTI, R. Bases para a leitura da violência. In: (Org.). Psicanálise e violência. Petrópolis: Vozes, 1992. (Org.). Psicanálise e violência. Petrópolis: Vozes, 1992.

BARRETO, V. Educação eviolência: reflexões preliminares. In:ZALUAR, A. Violênciaeeducação. São Paulo: Cor tez, 1992.

BÉVILLARD, S. Comprendre les jeunes: ruptures et émergence d'une nouvelle culture. Lyon: Chronique Sociale, 1998.

CAMACHO, Ma ria LuízaY. Violência ein dis ciplina nocotidia no es colardejo vens es tu dantes declas ses médias. São Paulo; 2000. Tese (Doutorado) - Faculdade de Educação da USP. 
CANDAU, V. M. Escola e violência. Rio de J aneiro: Dp\&A, 1999.

CARDIA, N. A violência urbana e a escola. Contemporaneidade e Educação, Rio de J aneiro, v. 2, n. 2, set. 1997.

CARNAJ AL, G. Tornar-se adolescente: a aventura de uma metamorfose (uma visão psicanalítica da adolescência). São Paulo: Cortez, 1998.

COLOMBIER, C. (Org.). A violência na escola. São Paulo: Summus, 1989.

COSTA, Heloísa H. A tra ma daviolência naescola. RiodeJ a neiro; 1993. Dis ser ta ção(Mes tra do)- IESAE/Funda ção Getúlio Vargas.

DEBARBIEUX, E. Le professeur el le sauvageon: violence à l'école, incivilité et postmodernité. Revue Française de Pédagogie, n. 123, avril-juin, 1998.

La violence em milieu scolaire 1: état des lieux. Paris: ESF, 1987.

. La violence em milieu scolaire 2: le désordre des choses. Paris: ESF, 1987.

Violence scolaire: la cote d'alerte. Le Nouvel Observateur, Paris, n. 1784, 14-20 jan. 1999.

ELIAS, N. 0 processo civilizador. Rio de J aneiro: J. Zahar, 1990. v. 1-2.

. Os estabelecidos e os outsiders. Rio de J aneiro: J. Zahar, 2000.

ENRIQUEZ, E. Da horda ao Estado. Rio de J aneiro: Zahar, 1990.

ERIKSON, E. Identidade, juventude e crise. Rio de J aneiro: J . Zahar,1971.

FACHINI, N. Enfoque psicanalítico da violência social. In: AMORETTI, R. (Org.). Psicanálise e violência. Petrópolis:Vozes, 1992.

FEIXA, C. De jóvenes, bandas y tribus. Barcelona: Ariel, 1998.

FIGUEIREDO, L. C. Ado lescênciaeviolência: considerações sobreo casobrasileiro. In: LEVISKY, D. L. (Org.). Adolescência pelos caminhos da violência. São Paulo: Casa do Psicólogo, 1998.

FLORO, M. Questions de violence à l'école. Ramonville Saint-Agne: Érés, 1996.

FORACCHI, M. A juventude na sociedade moderna. São Paulo: Pioneira, 1972.

FUKUI, L. Estudo de caso de segurança nas escolas públicas do estado de São Paulo. Idéias, São Paulo, n.21, 1994.

FURTER, P. J uventude e tempo presente: fundamentos de uma pedagogia. Petrópolis: Vozes,1975.

GIDDENS, A. Modernidade e identidade pessoal . Portugal: Celta ,1997.

. A constituição da sociedade. São Paulo: Martins Fontes, 1991.

GOFFMAN, E. A representação do eu na vida cotidiana. Petrópolis: Vozes, 1992.

GUIMARÃES, A. M. A dinâmica escolar: conflito e ambigüidade. Campinas: Autores Associados, 1996. A depredação escolar e a dinâmica da violência. Campinas; 1990. Tese (Doutorado) - UNICAM P . Aes colaea vi olên cia: relações entre vigilância, pu niçãoe de pre da ção es colar. Cam pinas; 1984. Dis ser ta ção (Mestrado) - PUC-Campinas.

GUIMARÃES, E. Cotidiano escolar e violência. In: ZALUAR, A (Org.). Violência e educação. São Paulo: Cortez, 1992. 
.Crônicadocotidianoes colar:violênciaees cola. EducaçãoeSociedade, Cam pinas, n. 38, p. 81-90, abr. 1991.

. Escolas, galeras e narcotráfico. Rio de J aneiro: Ed. da UFRJ, 1998.

(Org.). Violência e vida escolar. Contemporaneidade e Educação, Rio de J aneiro, v. 2, n. 2, set. 1997.

JELEN, C. La guerre des rues: la violence et "les jeunes". Paris: Plon, 1999.

KNOBEL, M. Normalidade, Responsabilidade e Psicopatologia da Violência na Adolescência. In: LEVISKY, D. (Org). Adolescência e Violência: conseqüências da realidade brasileira. Porto Alegre: Artes Médicas, 1997.

KUPFER, M.C. Violência da Educação ou Educação Violenta? In: LEVISKY, D. (Org.) Adolescência nos caminhos da violência. São Paulo: Casa do Psicólogo,1998.

LEVISKY, D. (Org.). Adolescênciaeviolência:conseqüências darealidadebrasileira. PortoAlegre:Artes Médicas, 1997.

(Org.). Adolescência pelos caminhos da violência. São Paulo: Casa do Psicólogo, 1998.

(Org.). Aspec tos do proces so de iden ti ficação do adoles centena socie dade contem porânea e suas re la ções com aviolềncia. In: 1997. . Adolescênciaeviolência: conseqüências darealidadebrasileira. Porto Alegre:Artes Médicas,

(Org.). Prefácio. In: . Adolescência e violência: conseqüências da realidade brasileira. Porto Alegre: Artes Médicas, 1997.

LUCAS, P. Pequeno relato sobre a cultura da violência no sistema escolar público em Nova York. Contemporaneidade e Educação, Rio de J aneiro, v. 2, n. 2, set. 1997.

MANNHEIM, K. Funções das gerações novas. In: FORACCHI, M. Educação e sociedade. São Paulo: Ed. Nacional, 1970. . 0 problema sociológico das gerações. In: FORACCHI, M. Mannheim. São Paulo: Ática, 1982.

MARQUES, M. 0. da S. Esco la no tur na e jo vens. RevistaBrasileiradeEducação.J uventudee Contemporaneidade, n. 5-6. Número especial.

MEZAN, R. A medusa e o telescópio ou Verggasse 19. In: Novaes, A. et al . 0 olhar. São Paulo: Cia. das Letras, 1989. . Ado les cên cia eViolên cia: APsica nálisenaPráticaSocial. In: LEVISKY, D. (Org.) Adolescência pelos caminhos da violência. São Paulo: Casa do Psicólogo, 1998.

OLIVEIRA, C. R. O fenômeno da vio lên cia em duas es colas: es tu do decaso. Por to Ale gre; 1995. Dis ser ta ção (Mes tra do)UFRGS/FE.

PERALVA, A. Escolaeviolêncianas perife rias urbanasfrancesas. ContemporaneidadeeEducação, Rio de J a ne i ro, v. 2, n. 2, set. 1997.

A violência urbana e a escola. Contemporaneidade e Educação, Rio de J aneiro, v. 2, n. 2, set. 1997.

PEREIRA, E.T. Brincar na Adolescência: uma leitura no espaço escolar. Belo Horizonte; 2000. Dissertação (Mestrado) Faculdade de Educação da UFMG.

RODRIGUES, A. S. Aes colasilen cio sa: aqui não há vio oência- umes tu do etno gráfico. Rio deJ a nei ro; 1994 . Dis ser tação (Mestrado) - PUC-RJ .

RUANO-BORBALAN, J .-C. (Org.). L'identifé (l'individu, le groupe, la société). Paris: Sciences Humaines, 1998.

SPOSITO, M.P. Estu dos so breju ven tu deem edu ca ção. Revis taBrasileiradeEducação.J uventudeeContemporaneidade, n. 5-6, 1997. Número especial. 
A instituição escolar e a violência. Cadernos de Pesquisa: Revista de Estudos e Pesquisa em Educação, São Paulo, n.104, 1998.

J ovens e educação: novas dimensões da exclusão. Em Aberto, Brasília, v.11, n. 56, out./dez. 1992.

Asociabilida de juvenilea rua: no vos conflitos, ação coletivada cidade. RevistadeSo ciologia daUSP, São Paulo, v. $1-2$, n. 5, p. 161-178, nov. 1994.

VALENÇA, V. L. C. A vio lên cia na es co la: da pal ma tó riaà vio lên cia sua ve. Perspectiva, Flo ri a nó po lis, v. 5, n. 10, p. 42-48, jan./jun. 1998.

VASCONCELOS, A. T. Violên cia e edu ca ção. In: LEVISKY, D. L. (Org.). Adoles cênciaeviolência: conseqüências darealidade brasileira. Porto Alegre: Artes Médicas, 1997.

VELHO, G. (Org.). Cidadania e violência. Rio de J aneiro: Ed. da UFRJ, 1996.

Violência e cultura: debates. Rio de J aneiro: Ed. da UFRJ , 1996.

WAISELFISZ, J. J . J uventude, violência e cidadania: os jovens de Brasília. São Paulo: Cortez, 1998.

WHITAKER, D. Violência na escola. Idéias, São Paulo, n. 21, 1994.

ZALUAR, A. A ilusão dos jovens e o crime organizado. Comunicação e Política, v. 1, n. 2, p. 231-250, dez./mar. 1995. (Org.). Violência e educação. São Paulo: Cortez, 1992.

Recebido em 16.07.01

Aprovado em 16.08.01

Carla Araújo é psicóloga, com especialização em Psicopedagogia, e mestra em Educação pela UFMG. É professora-assistente III pela PUC-MG/cam pus de BETIM e mi nis tra au las de Psi co lo gia da Edu ca ção nos cur sos de Le tras e Matemática dessa Insti tui ção bem comodaPUC-MG/BH. 